Article

\title{
From Medical to Human-Rights Norms: Examining the Evolution of Trans Norms in the Netherlands
}

\author{
Melisa Soto-Lafontaine \\ Institute of Management Research, Radboud University Nijmegen, 6500 HK Nijmegen, The Netherlands; \\ E-Mail:m.soto@fm.ru.nl
}

Submitted: 8 February 2020 | Accepted: 18 August 2020 | Published: 18 September 2020

\begin{abstract}
Examining the dynamics underpinning the evolution of trans norms in the Netherlands, from their emergence there in 1952 up until 2019, this article traces their development through four historical phases, each marked by notable milestones and supported by different sets of frames, actors, and norm-change mechanisms. My analysis shows that the normative profile of trans issues in the Netherlands has long been ruled by medical frames, but the last decades have also witnessed the emergence and establishment of a new set of frames rooted in human-rights discourses. By tracing the trajectory of trans norms in the Netherlands and examining the mechanisms underlying the emergence and changes of frames, this article contributes to the theoretical body of studies on norm diffusion by introducing the role of hybrid entrepreneurs, the dynamic co-assembling of medical and legal domains and the self-lead trans emancipation as a social entrepreneurial strategy.
\end{abstract}

\section{Keywords}

human rights; medical norms; non-state actors; norm entrepreneurship; norm diffusion; norm emergence; trans* rights; transgender politics; the Netherlands

Issue

This article is part of the issue "Trans* Politics: Current Challenges and Contestations" edited by Mieke Verloo (Radboud University, The Netherlands) and Anna van der Vleuten (Radboud University, The Netherlands).

(C) 2020 by the author; licensee Cogitatio (Lisbon, Portugal). This article is licensed under a Creative Commons Attribution 4.0 International License (CC BY).

\section{Introduction}

The dynamics in the diffusion of trans norms have only recently started to be examined as an exclusive object, separate from the collective LGBT domain (Balzer \& Hutta, 2014). Although trans issues might intersect with some LGB issues, there are specific differences between them. One example is the role of medical institutions and their discursive as well as material effects on trans people's realities. In the Netherlands, transnational medical frames have historically been present from the beginning. This article investigates the normative profile of trans issues, the role of these medical norms in the debates regarding trans policies, and the emergence and establishment of a new set of frames rooted in human-rights discourses.

The Netherlands has not only been a pioneer in gay rights but also a hegemon in transnational LGBT advo- cacy networks (Kollman, 2016; Osterburg \& Kiel, 2017). The country took the lead in providing medical care for trans people and became an authority in international knowledge production regarding trans health issues. In 2011, the Dutch state even launched a plan to increase the country's visibility as an international promotor of LGBT rights (van Bijsterveldt-Vliegenthart, 2011). Notwithstanding its reputation as international LGBT rights forerunner, however, the Dutch state was recently critiqued for its backwardness concerning the rights and protection of trans people (Human Rights Watch, 2013). In 2014, after Human Rights Watch's recriminations, the government amended the civil code to erase a legal stipulation that conditioned legal gender recognition to compulsory sex reassignment surgery and sterilization. These recent developments indicate a shift, as the Netherlands is no longer only engaged as a sender 
of trans medical norms but has also become a receiver of trans human-rights norms.

The purpose of this article is twofold: to trace the normative trajectory of trans issues in the Netherlands, and to examine the emergence and changes of these norms as a contribution to the theoretical body of norm diffusion. Departing from a constructivist approach (Benford \& Snow, 2000; van der Vleuten, van Eerdewijk, \& Roggeband, 2014), I here consider norms as discursive collective considerations of appropriate, correct, or desirable actions to 'solve' issues. They are the intended or unintended results of a series of dynamics involving multiple actors (individuals, collectives, institutions, states) that are mediated by multiple governing structures as well as historical and material contexts. The actors' engagement in this process can be understood as based on contestation. Through discursive frames they introduce ideas which aim to shape or influence social action. Studying the evolution of norms helps expose the interactions and mechanisms underlying social change. As it has been a pioneer in LGBT rights and networks, the focus of my study is on the Netherlands. Trans norms might seem relatively novel, but they have had an extensive trajectory in the Netherlands, spanning about seven decades and undergoing various changes implicating domestic and transnational political dynamics in the medical and legal domains. This makes Dutch trans norms a useful case to study the complex interplay of different processes underpinning norm change over time.

This article examines the political dynamics underlying the evolution of Dutch trans norms from their emergence in 1952 until 2019, and asks: How did trans norms emerge and change in the Netherlands? How are these normative changes related to changes in the actors involved? Which frames were used for contesting trans norms and what are the implications of these? And which mechanisms facilitated change and the prevalence of certain norms over others? I will answer these questions by describing the historical development of trans issues in the Netherlands, giving special attention to the actors as well as the frames and mechanisms that have shaped their normative character. My narrative is based on secondary sources on the history of trans care in the Netherlands. I also include primary sources, such as archival material, medical journals, as well as newsletters, reports, and statements from trans organizations. Finally, to supplement this historical account, I include data from two in-depth interviews held with key trans activists and advocates who played essential roles in Dutch trans activism during the late 1990s and 2000s. Their names have been anonymized in this article.

\subsection{Understanding Dutch Trans Norms Through Critical Frame Analysis and Norm-Diffusion Theories}

In order to understand the changes in Dutch trans norms, this article studies the evolution of the actions and normative principles of key actors aiming to 'solve' trans is- sues. Actors such as medical experts, legal experts, advocates, and activists disagree or concur in their understanding of trans rights problems, and they also engage in strategic actions to promote their solutions. Since 'trans norms' constitutes an empty signifier that is constantly changing because it "takes as many meanings as the variety of visions and debates on the issue allows it to take" (Verloo \& Lombardo, 2007, p. 22), I instead critically analyze the frames that actors have upheld and contested in the assemblages of trans rights norms in the Netherlands. Here, 'frames' are defined as arguments articulating the problems that trans rights, policies, and science ought to solve, and what sort of actions must be taken in order to effect these solutions (Verloo \& Lombardo, 2007).

Scholars in international relations have provided multiple theories to explain norm diffusion and state behaviors but only few seem to apply to the Dutch trans norms case. Rational approaches assume that states, following a cost-benefit logic, will only accept low-cost norms as they prefer norms that facilitate access to economic benefits (Kaufman \& Pape, 1999). Trans policies, however, can be costly for the state, and they do not grant access to economic opportunities. Early social constructivist approaches argue that states adopt new norms when they are spread by international institutions in the form of binding agreements that successfully stimulate the internationalization of new values and transform state actors' interests (Checkel, 1997). Yet in the Netherlands trans norms emerged before LGBT norms were developed at any international institution. In recent years, trans norms have been formulated in such documents as the Yogyakarta Principles, as well as in resolutions and issue articles by the Council of Europe and the UN, but they have not been codified in binding international agreements or treaties (Commissioner for Human Rights, 2009; Council of Europe, 2015; The Yogyakarta Principles, 2017; UN, 2011). Conventional international relations causal models that focus on states' interests and coercion from international organizations thus do not help to explain the timing and development of Dutch trans norms and policies. International relations constructivist theories (Finnemore, 1996; Partzsch, 2015; van der Vleuten, 2005) exploring the emergence of new norms, the actors shaping them, and the mechanism underlying further normative changes promise for a better explanation of the evolution of (Dutch) trans norms.

In the Netherlands, trans norms did not originate from the state, civil society, or activists. Rather, these processes were initiated by individual private health professionals who might not have powerful positions in the government but were involved in a transnational network of sexology experts. The norms were further developed by other individuals such as lawyers, physicians, and managers of institutions sharing humanitarian moral principles and social commitment. The literature has typically regarded non-state political actors as individuals from social movements aiming to push forward 
norms by actively persuading governments (Finnemore, 1996; Finnemore \& Sikkink, 1998), usually labeling them 'norm entrepreneurs.' More recent publications have also noted 'social entrepreneurs,' a novel type of nonstate actor that, instead of focusing on governmental institutions, opts to implement innovative actions affecting society directly (Partzsch, 2015). These two types of 'entrepreneurs' have been crucial throughout the development of Dutch trans norms. In fact, their emergence and evolution introduce a new breed of actors who are yet to be considered in the theory around norm entrepreneurs. Professionals involved in the emergence of trans norms played roles that resemble a hybrid of these two types of entrepreneurs.

Through the history of Dutch trans norms, we can also observe how certain domestic and transnational actions taking place within the medical professions were crucial in ensuring the persistence of the trans medical regime. By building scientific credibility and prestige through the development of specialized knowledge, medical professionals succeeded in sustaining the state's commitment to support trans care rights, but at the same time they also strengthened the trans medical regime and preserved the binary sex-gender regime in Dutch law. This co-assembling dynamic between the medical and the legal domains can certainly contribute to theories of norm-diffusion mechanisms.

Theories of 'state identities' are also useful to understand the mechanisms contributing to more recent Dutch trans-norm changes. Anna van der Vleuten's 'pincers and prestige' theory explains how states are more willing to accept new norms when their prestige is at risk and when the state is simultaneously put under pressure by national and supranational actors (van der Vleuten, 2005). In the next section I will consider whether the amendment of the Dutch Civil Code in 2014 that eliminated the requirement of sterilization for legal gender change can be explained as an outcome of such a political mechanism.

\section{Four Historical Milestones in Dutch Trans Norms}

When it comes to Dutch trans issues, this article distinguishes four historical phases marked by developmental milestones. The first phase, 1952-1959, is marked by the emergence of the first normative debates surrounding the introduction of sex-reassignment surgeries in the country. The second, 1960-1979, is characterized by the actions of a network of social and norm entrepreneurs that succeeded in establishing the first institution tackling trans-norm change; their efforts materialized in the first trans legislation. The third, 1980-1999, is typified by the implementation of a trans law through the development of scientific knowledge and the standardization of clinical procedures. The fourth and last phase, 2000-2019, is distinguished by the intensification of domestic and transnational trans advocacy actions linked to the emergence of a trans human-rights regime.

\subsection{2-1959: First Surgeries and Contestations}

Alex Bakker's account of the history of transgender issues in the Netherlands proposes that medical attention to trans issues was first triggered by Christine Jorgensen's emergence as an international media phenomenon (Bakker, 2018, p. 17). Jorgensen, a US citizen, successfully underwent hormonal treatment and gender-affirming surgeries in Denmark in 1952. When her case's international attention prompted a high number of consolation requests from people around the world, Jorgensen's Danish doctor, Christian Hamburger, reached out to various sexologists abroad, such as Hans Guise in Hamburg, Harry Benjamin in New York, and Coen van Emde Boas in Amsterdam, asking them to join him (van Emde Boas, 1974, pp. 17-19).

In the Netherlands, psychiatrist and sexologist van Emde Boas had acquired a reputation of being a progressive practitioner interested in dealing with sexuality issues (Bakker, 2018). In fact, he coined the term 'transseksist,' which served as an inspiration for Benjamin's terms 'transsexual' and 'transsexualism' (Benjamin, 1966). After joining forces with Hamburger, van Emde Boas reported treating about 40 patients between 1954 and 1956, all US citizens sent by Benjamin to continue gender transition in the Netherlands (van Emde Boas, 1974, p. 475).

The fact that van Emde Boas was allowed to perform such interventions in collaboration with other physicians did not mean that there were no normative debates in the Dutch medical field. In the scientific journal Nederlands Tijdschrift voor Geneeskunde (Dutch Journal of Medicine, author's translation), practitioners from different fields engaged in debates concerning sex-reassignment surgeries. While supporters employed compassionate arguments to justify genderaffirming care interventions (Plate, 1954), detractors argued for a psychopathological approach and framed gender non-conforming expressions as delusional disorders, and advised psychological help for self-acceptance (Carp, 1954).

The psychopathological framework was backed by the international medical regime of the World Health Organization (WHO) and the American Psychiatric Association (APA). In 1948, the WHO included 'homosexuality' in the sixth version of its International Classification of Diseases and Related Health Problems (ICD-6; Cochran et al., 2014). Gender identity and sexual orientation were conflated in this document, and its diagnosis of, and approach to, homosexuality were applied to gender variance as well. Likewise, in 1952, the APA added 'homosexuality' and 'transvestism' in the first edition of its Diagnostic and Statistical Manual of Mental Disorders (DSM), classifying both as sociopathic personality disturbances (APA, 1952). In the same period, Benjamin, who was already famous due to his involvement in Jorgensen's case, defied that international psychiatric regime, and introduced the rubric 'transsexu- 
alism' and the clinical use of gender-affirming surgeries (Benjamin, 1954).

In the Netherlands, gender-affirming practices came under attack after the first publicly known 'female-tomale' sex reassignment surgery took place at Arnhem's Municipal Hospital in 1959. The German client, who had first undergone a series of interventions in Germany and South Africa, came to van Emde Boas to complete his transition (Haeseke \& Nicolai, 2007). Plastic surgeon Siebren Woudstra presented his case to a group of colleagues who, after intense deliberation, approved the removal of the client's uterus on the grounds of compassionate Christian ethics (van Emde Boas, 1974). Despite this approval, hardly anyone at the Municipal Hospital wanted to be involved in the process. The Dutch medical community was even outraged at the idea of having surgeons treating psychiatric illnesses and found the intervention violated medical ethical principles of protecting a patient's physical integrity (Steenwinkel, 1960). The case caused great commotion, and gender-affirming surgeries became rare as hospital managers started forbidding them (Haeseke \& Nicolai, 2007).

In this first phase, the Dutch framing of trans issues emerged along with a sudden international demand for gender-affirming surgeries. People with trans experiences were seeking help across the world, and in the Netherlands a very small group of medical experts already engaged in an international sexology network expanded this innovative medical practice. The normative debate surrounding this new practice was constrained to the medical community. Practitioners favoring the application of new techniques to modify the bodies of gendervariance clients called for medical virtues such as empathy and compassion. Opponents employed a psychiatric epistemic frame that followed the international medical paradigm and condemned medical doctors willing to perform gender-affirming surgeries for crossing their specialization's boundaries and harming the individuals' bodily integrity. They called for the protection of the profession's integrity and defended conversion therapy as the preferable (if not only) solution.

\subsection{0-1979: Disobedient Entrepreneurs, Institutionalization, and Norm Change}

In 1965, the debate surrounding the Arnhem case provoked the Ministry of Social Affairs' intervention, requesting the Health Council's opinion on the validity of gender-affirming surgery for treating a psychiatric condition. Following Verschoor (1983), with this the Ministry intended to advocate for the criminalization of sex reassignment surgeries. An evaluation committee was established to consult medical professionals and university professors, but trans individuals were not included in the formal discussion (Everaerd, 2014). The committee, which was comprised of 'conservative' medical professionals with no experience with trans people, decided that gender variance was a manifestation of a mental dis- order (de Vaal \& Lamaker, 1982). The committee recommended conversion therapy and, as operations were not considered a medical necessity, the Ministry of Justice banned gender-affirming surgery-though they notably did not criminalize it (Verschoor, 1983). Consequently, trans people were sent to psychiatrists, and their experiences were labelled as psychotic expressions of unresolved sexual anxieties (Verschoor, 1983), in line with the Health Council's definition and the transnational medical regime. Conversion therapy in the form of longterm psychoanalysis became the main medical advice, and some individuals underwent electroshock therapy (Meulmeester, Bos, Spaas, \& Eisfeld, 2005). While doctors could still help without confronting juridical penalties, gender-affirming surgeries were not carried out for several years (Verschoor, 1983).

At the same time in Amsterdam, a network of progressive care professionals was developing into a political force, paving the way for the institutionalization of gender-affirming care and norm change. Endocrinologist Otto de Vaal is credited as the architect of this network and the founding father of Dutch trans care (van Garrel, 1992). In his book Man of Vrouw? Dilemma van de Transseksuele Mens (Man or woman? The Dilemma of Transsexual People, author's translation), de Vaal (1971) actively criticized the validity of the dominant psychiatric approach in the Netherlands, and in other publications he deemed the psychiatric frame "reactionary," "non-scientific," "creationist," and "theological" (de Vaal \& Lamaker, 1982, p. 715). He also used the concept of 'being trapped in the wrong body'-which was still incipient in the international debate-to describe the emotional suffering of trans people, and explored various genetical, chromosomal, and hormonal hypotheses, marking the introduction of a biology paradigm in the Dutch debate (Bakker, 2018). Despite the Ministry of Justice's ban and the dominant taboo regarding sexreassignment surgeries within the medical community, de Vaal and his spouse Liselotte Demmers opened their home in Amsterdam to a group of trans people, many of them sex workers. They also distributed second-hand women's clothes, prescribed hormones, offered general medical care, coordinated surgeries, and helped with legal assistance when trans people tangled with the police. Aware of their clients' precarious living conditions, they did not charge for their services and even arranged a solidarity fund to cover special care costs (Bakker, 2018; van Garrel, 1992).

In 1972, the director of sanatorium Beatrixoord in Amsterdam, Geertruida Wijsmuller-Meijer (also known as 'Aunt Truus' for saving the lives of non-Aryan children during WWII), together with de Vaal, Demmers, and surgeon Philip Lamaker created the country's first organization offering a clinic for trans people in Amsterdam: Genderstichting (Gender Foundation, author's translation). Their progressive vision of care also addressed social issues such as work and housing (Bakker, 2018). The other founders of the Genderstichting were also re- 
spected professionals with affiliations to important institutions: Koos van de Werff was a professor of endocrinology at Leiden University; Arie de Froe was the rector of University of Amsterdam; and Jan Allema was chairman of the health insurance fund council (Meulmeester et al., 2005). Their interest in trans issues varied substantially, but they seemed unified by shared humanistic values. For instance, though de Froe did not know much about trans issues, he endorsed the clinic out of respect and loyalty to fellow veterans involved in its conception (Bakker, 2018). The organization maintained such a good reputation that they managed to arrange cost coverage for hormonal treatment and surgeries through the national health service (van Garrel, 1992).

The Genderstichting was also essential in their provision of legal support. Already since 1971 lawyers Ida Neumann and Frans van der Reijt began to strategically appeal to Article 21 of the civil code, which allowed correcting errors in Dutch birth certificates, to enable their trans clients to change their legal gender markers (de Vaal \& Lamaker, 1982). For this, they used the precedent of two 1963 cases. In the first case, a trans person who underwent sex-reassignment surgeries in Casablanca, Morocco, and was granted permission for changing their name in the Netherlands, managed to convince the court that changing the birth certificate's gender marker was also needed for enabling the opportunity to lead "a normal life" (de Vaal \& Lamaker, 1982, p. 693). The second case involved an intersex person who was allowed to change their birth certificate after their solicitor used medical declarations explaining how the appearance of his client's genitals changed from female to male after puberty. In the new petition, Neumann and van der Reijt also presented medical declarations, some of them including photos of their clients' naked bodies (Bakker, 2018). Their strategy, which mimicked that of the intersex case, worked well, as lower courts assumed that after hormonal treatment and sex-reassignment surgery the clients would be deemed as part of opposite gender "on the basis of their essential characteristics" (de Vaal \& Lamaker, 1982, p. 693). For three years, dozens of cases ruled in favor of the Genderstichting and its clients until 1974, when the Dutch supreme court overruled over a number of cases under the guise of "protecting the integrity of the law" (de Vaal \& Lamaker, 1982, p. 693).

After the medical battle, the legal battle now gained momentum. Bothered by the negative juridical turn, de Vaal managed to pull some strings and set a meeting with the minister of justice (de Vaal \& Lamaker, 1982). Afterwards, that minister ordered the establishment of a judicial commission and the constitution of a new health council's expert committee in which eight of the nine members had actual practical experiences with trans patients (Orobio de Castro, 1993). The commission concluded that "somatic adjustments were an essential part of a treatment plan that could offer the greatest chance for reducing the existential suffering" of trans people
(Verschoor, 1983, p. 26), adding a novel psycho-social component to the framing of Dutch trans norms.

Van der Reijt joined a second sub-commission tasked to develop a legal proposal for changes to birth certificates. The sub-commission invited the first Dutch trans organization Travestie \& Transseksualiteit (TenT, Transvestite and Transsexuality, author's translation) to provide feedback, for the first time opening the conversation to trans community representatives (Bakker, 2018). TenT had an emancipation agenda focused on community support, social inclusion, and self-acceptance issues (Meulmeester et al., 2005). The sub-commission proposed that changes to the birth certificate could be made on the following conditions: 1) A statement from an expert; 2) a 'real life test' of one year minimum; 3) sexreassignment surgery and sterilization; and 4) unmarried status at the moment of requesting the legal change. TenT and van der Reijt voiced their opposition against all of these except the marriage condition, since after legal gender reassignment married applicants would have had transformed their marriages into a same-sex format, which was not yet sustained by the Dutch marriage law. The trans collective criticized the mistrust implicit in the 'real life test' and questioned how someone could be considered more expert than trans people themselves (Bakker, 2018, p. 131). Van der Reijt added that, since the legislation was based on the notion of gender identity, self-diagnosis was the only way to truly determine if someone was 'transsexual.' He also expressed perplexity at the sterilization requirement, warning that the requirement was an unjustifiable violation of trans people's physical integrity and calling the argument that sterilization would protect the welfare of future children 'unrealistic.' He asked: "What is the difference between having a parent who later decides to change their gender or being born from a parent who had already their gender changed?" (van der Reijt, 1982, p. 117). Despite his concerns, van der Reijt still implored the legislation be quickly approved, as it would guarantee the "human rights" of trans persons (van der Reijt, 1982, p. 118). The four requirements were included in the first Dutch law on gender changes in legal documents, which was finally implemented on 1 August, 1985.

The first Dutch trans legislation thus resulted from the humanitarian commitment and action of a network of diverse, respectable actors. Instead of investing their energies in lobbying strategies, they opted for disobeying the Ministry of Justice's ban. They engaged in solidarity action to improve the social reality of trans people. Dignity, justice, solidarity, and human rights were the key principles underlying their actions. As actors they were social entrepreneurs committed to fostering social change by building change from the bottom. They created a foundation and employed a strategy to softly rupture the jurisprudence and institutional psychiatric regime, moving towards new legal recognition and citizenship structures for gender-variant individuals. After confronting the court's limitations, however, their role 
changed to that of norm entrepreneurs seeking actual norm change in government regulation. Their work resulted in the first legislation explicitly addressing trans issues. The law attributed the trans 'problem' to the individuals' bodies, and postulated it ought to be solved by medical science. The frame of being trapped in the wrong body that highlights the biological aspects of gender variance, was successfully integrated in the law that sought to alleviate the existential suffering through physical adjustments instead of psychoanalysis, conversion therapy, and other psychiatric interventions.

Although the norm change that took place between 1960 and 1979 in the Netherlands was not underpinned by a formal transnational network of actors, the international diffusion of new scientific ideas that challenged the hegemonic power of psychopathology was having a strong effect in the domestic debate. The advanced ideas that de Vaal, van der Reijt, and their colleagues promoted corresponded with the fundamental normative shifts also taking place in the international scientific arena (de Vaal \& Lamaker, 1982): In the US, Robert Stoller introduced the distinction between sex and gender (Stoller, 1968) and both Harry Benjamin as well as Richard Green and John Money published the first guidelines for gender transitioning care (Benjamin, 1954; Green \& Money, 1969); in the UK, Norman Frisk coined the term 'gender dysphoria syndrome' to conceptualize the distress that 'transsexual' people experienced (Frisk, 1974); and in 1973 'homosexuality' was removed from the APA's DSM after intense political activism denunciating the fact that the psychiatric approach contributed to social stigma (Drescher, 2015).

\subsection{0-1999: Formalization, Credibility, and Strengthening the New Norm}

1979 saw a change of leadership at the Genderstichting that instigated a new approach and framework. Due to internal disagreements, the initial group dissolved the original foundation and re-founded it headed by van der Reijt in partnership with clinical psychologist Anton Verschoor from the Free University Hospital in Amsterdam (VUmc; de Vaal \& Lamaker, 1982). Verschoor was already known for his leadership in sexual-reform activism and his commitment to gender-variant people. Together with endocrinologist Louis Gooren, Verschoor invested in standardizing their care practice, and at the VUmc they soon built the first trans polyclinic and research center in the world, known today as the Center of Expertise on Gender Dysphoria. Developing research and knowledge were central to their agenda for concretizing and solidifying this practice in defense against public criticism and skepticism from the medical community (Willems, 2013). They used the biological and psychological sciences both to increase social acceptance and to justify getting their costs covered. Using knowledge from these fields to develop a diagnosis, was, according to Gooren, vital for obtaining the health insurance companies' commitment to covering the costs of gender-affirming care (Bakker, 2018, pp. 154-155). The standardization process included developing a new diagnostic and trajectory guideline that integrated the law's requirement for a real-life test and allocated a gatekeeper role to medical doctors.

During the 1980s, trans care in the Netherlands had become robust. Everything related to gender transitioning could be arranged. Hospitals in Rotterdam, Arnhem, and Groningen helped deal with the growing demand, but under the VUmc team's watch (Bakker, 2018). The academic hospital in Groningen was the only hospital that developed an independent team of experts. In line with the advice of the Health Council's expert committee to tackle the lack of studies on treatment efficacy and the longitudinal effects of gender-affirming interventions, the number of Dutch researches increased exponentially (Everaerd, 2014).

These rapid structural and scientific developments coincided with the 1980 inclusion of Benjamin's term 'transsexualism' and the 'gender identity disorder' classification in the DSM III (Pauly, 1993). This was a pivotal development in international trans medical norms, and Dutch medical experts contributed significantly. In the international scientific world, the Netherlands' reputation in the field grew towards greater internationalization and prestige. In 1987, Amsterdam hosted the tenth symposium of Harry Benjamin's International Gender Dysphoria Association (later named World Professional Association for Transgender Health [WPATH], 2019), where Dutch clinical care practices and knowledge were diffused. The VUmc's Center of Expertise hosted specialists from all over world (Bakker, 2018), joined in international research collaborations, and their work was increasingly cited in global medical studies. In their approach, cognitive and developmental psychology triumphed over the psychiatric frame. Dutch endocrinology played an essential role in the development of trans care guidelines internationally. Studies focused on the body as the root cause of problems with gender identity were also abundant. During the second half of 1990s, clinical psychologist Peggy Cohen-Kettenis began a clinical approach that facilitated gender-affirming care trajectories to adolescents, making the Netherlands the first to offer pediatric transitioning care in Europe (Cohen-Kettenis, 2013). Internationally known as 'the Dutch protocol' today, this program has been diffused around the world and incorporated in the WPATH's Standard of Care and the Endocrinology Society's clinical guidelines (Cohen-Kettenis, 2013).

Meantime, between 1983 and 1999, 20 new trans organizations were founded in the Netherlands. The collectives ranged from Christian groups and transmen-exclusive organizations, to trans homosexual collectives and trans self-representation in trade unions (Meulmeester et al., 2005). Amongst this growing number of collectives, there was little focus on political actions such as advocacy and activism. The majority were limited to a self-help group format focused on issues of 
social acceptance, community building, and knowledge exchange (Meulmeester et al., 2005). The trans activists I interviewed for this study explained that at that time an activist "social acceptance" aimed to "humanize trans people, beyond the helpless sick psychiatric" stereotype (personal communication, September 7, 2017) through facilitating guidance for "becoming respectable members of the society" (personal communication, May 23, 2018).

This third phase in the development of Dutch trans norms also included additional practices and frameworks that affected norm changes. The process was essential for standardizing the implementation of the 1985 trans law, as well as for increasing norm acceptance in the medical spheres and general society, and for ensuring the public cost coverage of trans medical care. Rather than guaranteeing special rights to trans people, the medical standardizations and the law primarily and strongly operated as shields safeguarding the perpetuation of the binary sex-gender regime. This can also provide a clue as to its success, and the process underscores the important collaboration between medicine and law in the assemblage of a trans medical norm which resonated strongly with the cis-heteropatriarchal normative order and therefore was more likely to be internalized in society.

\subsection{0-2019: Transnational Trans Activism, the Establishment of the Trans Human Rights Norm, and the Self-Led Trans Emancipation}

At the start of the new millennium, the number of trans collectives was still rising, displaying more sophisticated political outlooks on further developing significant normative changes. In 2004, $T^{3}$ ( $T$ with a third exponent referring to transsexual, transgender, and transvestite), the first Dutch national conference for trans organizations, took place in Amsterdam. The event aimed to tackle the lack of trans self-representation in policymaking and envisioned consolidating all collectives into a unifying political power. After the event, the organizers published a booklet that listed at least 32 Dutch trans groups (Meulmeester et al., 2005).

As an outcome of the conference, Transgender Network Nederland (TNN) emerged in 2006, a national umbrella organization that soon was formalized into the first Dutch trans advocacy group financed by the Ministry of Education, Culture, and Sciences. In the TNN agenda, the social-acceptance frame evolved into a frame of 'social transformation.' Instead of locating the problem in trans individuals, they pointed to the 'social structures' at the root of the inequalities that trans people suffered in Dutch society (personal communication, September 7, 2017). Advocacy in the form of education for civil-society organizations was their first step towards normative change, and they incorporated the amendment of trans legislation as a priority issue. As of 2019, TNN had successfully expanded trans visibility in Dutch society, and through establishing important alliances domestically and transnationally they opened the space for trans self-representation in essential decisionmaking processes tackling issues of health, social inequality, and discrimination.

At the international level, the adoption of the Yogyakarta Principles in 2006, which stipulates that gender identity, body self-determination, and reproductive autonomy are inalienable elements of human dignity, marked the human-rights turn of transgender politics globally. These principles have been embraced in the international trans depathologization agenda that continues today. Advocates argue that erasing gender variance from the international classification of diseases (such as the APA's DSM and the WHO'S ICD) is essential to tackle the discrimination and social inequalities harming the wellbeing and integrity of trans people worldwide. Moreover, the principles have also been used to frame the transnational trans agenda that targets changes in domestic legislation and policies, particularly equal rights, protection against discrimination, adequate healthcare, and legal recognition of one's gender identity without conditions of coercive body modifications and sterilization.

In 2009, the Council of Europe's Human Rights Commissioner (2009) issued an article detailing EU member states' inadequate institutional handling of gender identity issues. The Council later developed recommendations for combating discrimination on the grounds of gender identity in 2010 (Council of Europe, 2010). In 2011, these rights were included in the first UN resolution addressing sexual orientation and gender-identity rights (UN, 2011).

This transnational trans human-rights momentum had a ripple effect on Dutch trans rights issues, accelerating significant normative changes. In 2008, citing the Yogyakarta Principles, TNN requested the abolition of the sterilization requirement, with no resulting action from the Ministry of Justice. In 2011, however, the Dutch house of representatives announced the preparation of a draft bill entitled Transsexualiteit (transsexuality), which explicitly included the Council of Europe's recommendation to abolish the sterilization requirement (van Bijsterveldt-Vliegenthart, 2011). In the same year, TNN, together with the large Dutch LGBT federation Cultuur en Ontspanning Centrum (Center for Culture and Leisure, author's translation) and the international LGBT organization ILGA-Europe, submitted a review of LGBT rights in the Netherlands to the UN, requesting the abolition of the Dutch sterilization requirement. Human Rights Watch published a report that also condemned the sex-reassignment surgery and sterilization requirement in the Netherlands. The report "Controlling Bodies, Denying Identities: Human Rights Violations against Trans People in the Netherlands" (Human Rights Watch, 2011) touched the core of the Dutch state's identity, as it affected its precious "role model position in international LGBT rights" (van Bijsterveldt-Vliegenthart, 2011, p. 3) The fact that in 2008 the state did not act on 
TNN's demands in 2008 points out that the pressure of a domestic trans network alone was not enough to achieve the normative change. Only transnational shaming, in combination with domestic and transnational pressure, built up a substantial enough risk burden to the state's international image as an LGBT role model that the norm was changed. This confirms van der Vleuten's (2005) theory of a 'pincers and prestige' mechanism that states adapt when they are facing local activists' demands as well as international pressure regarding the state's identity and ego.

Moreover, the human-rights norms of personal autonomy and self-determination were also employed to frame abolishing the requirement of an 'expert opinion' when changing the gender markers on birth certificates as well as in the demands towards decentralizing the national Dutch trans healthcare; in other words, the despecialization of trans care by care services beyond expert teams such as the VUmc and the academic hospital in Groningen. With this agenda, local activists used innovative strategies to pave the way towards more transformative structural reforms. In 2016, during WPATH's 24th biannual conference in Amsterdam, a group of trans activists held a parallel symposium event titled Free PATHH: Practicing Actual Trans Health and Human Rights to promote their demands for personal autonomy and the right to self-determination in trans care on the grounds of trans human-rights principles. Furthermore, in 2018, the Trans United collective for trans people of color together with the Dutch sex-workers union, started the first trans-led Dutch clinic, where people can continue or start gender-affirming care trajectories without the requirement of psychological evaluations, exercising full autonomy in their transitioning processes. The clinic started as a solution to the lack of healthcare access and legal support for the most marginalized trans people, such as undocumented migrants, asylum seekers, and sex workers. Their services have now extended to address the whole trans community. The trans collectives Principle 17 and Trans United have worked with trans individuals to investigate and make visible the negative experiences of trans people within the official Dutch trans healthcare system and its conflicts with human rights standards (Lima, Manichard, \& Reyes, 2017; Principle 17, 2016).

These examples highlight a new wave of Dutch trans politics, in which trans people are no longer seen as mere objects of medicine and research; instead, they occupy the roles of experts, care providers, and political actors. In their self-lead trans emancipation agenda they act also as social entrepreneurs seeking, through direct social action, structural social changes to improve their own lives. In summary, the trans human-rights frame is not only applied in contesting the medical regime within the depathologization agenda, but also in a more proactive framing of the broader Dutch trans emancipation agenda. Although the medical frame still plays an essential role in the Netherlands, it no longer occupies a hegemonic position. Instead, contemporary Dutch trans poli- tics and policies are completely in line with the humanrights norm and tools such as the Yogyakarta Principles.

\section{Conclusions}

This article described the evolution of Dutch trans norms from their domestic emergence in 1952 up until their developments in 2019. It began by asking: How did trans norms emerge and change in the Netherlands? How are these normative changes related to changes in the actors involved? And what mechanisms facilitated change and the prevalence of certain norms over others? The article addressed these questions by describing the historical development of trans issues in the Netherlands, giving special attention to the actors as well as their normative frames and the mechanism that shaped these. In so doing, it describes eight distinctive frames contesting trans norms.

The advent of sex-reassignment surgery in the Netherlands marked the emergence of trans norms contestation. This medical technological innovation introduced a new care paradigm centered on Christian medical virtues. It called medical professionals to act upon a compassionate care approach (1) and challenged the well-established transnational psychopathology paradigm (2) that located the problem in individuals' mental health. This psychopathology norm did not change until the involvement of a network of non-governmental actors that assumed a hybrid entrepreneurial role and drove social change by combining direct action with advocacy. Their being trapped in the wrong body (3) frame located the origin of the problem in trans individuals' bodies. This frame designated integrity in gender identities and proposed body modifications as a solution to the 'existential suffering' trans people experienced. Contesting the frame clinical diagnosis, real-life tests, and expert declaration (4), which was introduced in the first Dutch legislation and later enacted by medical standardization, they suggested self-diagnosis (5). This emphasized individuals' sovereignty over their own identity; in other words, they argued that nobody commands another person's gender identity. However, worrying to miss the opportunity for establishing the first set of trans rights, they refrained from promoting this frame more extensively. This self-diagnosis frame resonated strongly with the trans human-rights frame (6), which stipulates that gender identity, bodily self-determination, and autonomy are fundamental elements of human dignity. Trans activists operated with two different emancipation frames. Emancipation through social acceptance (7) intended to 'humanize trans people' by making them 'respectable members of society.' It located the problem in individuals' attitudes instead of society and its structures. Then came the self-led trans emancipation (8) agenda, which incorporated the human-rights normative principles of personal autonomy and self-determination, and located the problem in the social structures perpetuating cis-heteronormativity, such as medical institutions. As a 
solution, it proposes that trans people should occupy crucial roles in the provision of care, in decision making, as well as in the production of knowledge. This has been unfolded in the form of social entrepreneurship. Instead of exclusively focusing on advocacy work for attaining better policies, domestic trans activists engage in a series of self-lead trans emancipation action seeking to improve their own realities directly.

The case of Dutch trans norms also proves useful for understanding how a norm can gain strength and social validity through the production of scientific knowledge that is embedded in international medical regimes, mainly when it guarantees the safeguarding of long-established normative order. In the Dutch trans norm case, such a norm-strengthening dynamic was highlighted by the assembling processes that took place during the first trans law's implementation. The state granted trans people legal recognition with specific restrictions to protect the law against the undermining of the binary sex-gender regime. Medical standardization, as well as care guidelines, were used to guarantee its preservation and perpetuation. The final amendment of the trans law, however, demonstrated that even the hegemonic position of the most solidly established norms could be defeated. Emerging norms are more likely to prevail when their framings include principles with strong international resonance (such as the humanrights and the Yogyakarta Principles) and are encouraged through a transnational strategy that puts pressure on the state's ego by actions in both domestic and supranational arenas (van der Vleuten, 2005).

\section{Acknowledgments}

I will like to thank the participants of the European Conference of Politics and Gender 2019 in Amsterdam, the early-career workshop "Studying Sexuality, Politics and Activism" 2019 at the University of Amsterdam, and the PhD seminar Gender \& Diversity 2019 at the Radboud University Nijmegen for their useful feedback on my initial drafts of this article. I want to specially thank Mieke Verloo, Anna van der Vleuten, Joz Motmans, Phillip Ayoub, Marleen Reichgelt, and Anouk Evers, as well as Melissa Weiner and Blake Kendall for their valuable comments on earlier versions of this article. I am also grateful to the two anonymous reviewers for their constructive criticism and suggestions. Last but not least, I want to thank the two trans activists and advocates who kindly accepted to be interviewed for this project.

\section{Conflict of Interests}

The author declares no conflict of interests.

\section{References}

American Psychiatric Association. (1952). Diagnostic and statistical manual of mental disorders. Washington,
DC: American Psychiatric Association.

Bakker, A. (2018). Transgender: Een buitengewone geschiedenis in Nederland [Transgender: An extraordinary history in the Netherlands]. Amsterdam: Boom.

Balzer, C., \& Hutta, J. S. (2014). Trans networking in the European vortex: Between advocacy and grassroots politics. In P. M. Ayoub \& D. Paternotte (Eds.), LGBT activism and the making of Europe: $A$ rainbow europe? (pp. 171-192). London: Palgrave Macmillan.

Benford, R., \& Snow, D. A. (2000). Framing processes and social movements: An overview and assessment. Annual Review of Sociology, 26(1), 611-639.

Benjamin, H. (1954). Transsexualism and transvestism as psychosomatic and somato-psychic syndromes: Symposium. Am. J. Psychother, 8(2), 219-230.

Benjamin, H. (1966). The transsexual phenomenon. New York, NY: The Julian Press.

Carp, E. A. (1954). Transvestitisme [Transvestism]. Nederlands Tijdschrift voor Geneeskunde, 98(2), 1474-1477.

Checkel, J. (1997). International norms and domestic politics. European Journal of International Relations, 3(4), 473-495.

Cochran, S. D., Drescher, J., Kismödi, E., Giami, A., GarcíaMoreno, C., Atalla, E., . . . Reed, G. M. (2014). Proposed declassification of disease categories related to sexual orientation in the International Statistical Classification of Diseases and Related Health Problems (ICD-11). Bull World Health Organ, 92, 672-679.

Cohen-Kettenis, P. (2013). Agendering voor het nageslacht [An agenda for posterity]. Amsterdam: Free University Hospital in Amsterdam.

Commissioner for Human Rights. (2009). Human rights and gender identity. Strasbourg: Council of Europe.

Council of Europe. (2010). Recommendation (CM/Rec(2010)5) of the Committee of Ministers to member states on measures to combat discrimination on grounds of sexual orientation or gender identity. Strasbourg: Council of Europe.

Council of Europe. (2015). Discrimination against transgender people in Europe (Resolution 2048). Strasbourg: Council of Europe. Retrieved from https://pace.coe.int/pdf/f591158caf9e8686df66bd7 cfa3326643ecd73a43326667a8259ffe25682ae8484 28feba12/resolution\%202048.pdf

Council of Europe's Human Rights Commissioner. (2009). Issue paper human rights and gender identity (Issue Brief No. 2). Strasbourg: Council of Europe.

de Vaal, O. (1971). Man of vrouw?: Dilemma van de transseksuele mens [Man or woman? The dilemma of transsexual people]. Amsterdam: Wetenschappelijke Uitgeverij.

de Vaal, O., \& Lamaker, J. (1982). Transsexualiteit in Nederland: Wat er aan het wetsontwerp voorafging [Transsexuality in the Netherlands: What preceded the bill]. Medisch Contact, 37(23), 691-693.

Drescher, J. (2015). Out of DSM: Depathologizing homo- 
sexuality. Behavioral Sciences, 5(4), 565-575.

Everaerd, W. (2014). Preface. In K. P. Baudewijntje, T. D. Steensma, \& A. L. de Vries (Eds.), Gender dysphoria and disorders of sex development: Progress in care and knowledge (pp. i-xxxii). New York, NY: Springer.

Finnemore, M. (1996). Norms and war: The international Red Cross and the Geneva conventions. In M. Finnemore (Ed.), National interests in international society (pp. 69-88). London: Cornell University Press.

Finnemore, M., \& Sikkink, K. (1998). International norm dynamics and political change. International Organization, 52(4), 887-917.

Frisk, N. M. (1974). Gender dysphoria syndrome: The conceptualization that liberalizes indications for total gender reorientation and implies a broadly based multi-dimensional rehabilitative regimen. The Western Journal of Medicine, 120(5) 386-391.

Green, R., \& Money, J. (1969). Transsexualism and sex reassignment. Baltimore, MD: The John Hopkins University Press.

Haeseke, B., \& Nicolai, J. A. (2007). De eerste geslachtsveranderende operatie van vrouw naar man in Nederland, 1959/'60 [The first gender reassignment surgery from woman to man in the Netherlands]. Nederlands Tijdschrift voor Geneeskunde, 151(9), 548-552.

Human Rights Watch. (2011). Controlling bodies, denying identities: Human rights violations against trans people in the Netherlands. New York, NY: Human Rights Watch.

Human Rights Watch. (2013). The Netherlands: Victory for transgender rights. Human Rights Watch. Retrieved from Human Rights Watch: https://www.hrw. org/news/2013/12/19/netherlands-victorytransgender-rights

Kaufman, C., \& Pape, R. (1999). Explaining costly international moral action: Britain's sixty-year campaign against the Atlantic slave trade. International Organization, 53(4), 631-668.

Kollman, K. (2016). Pioneering marriage for same-sex couples in the Netherlands. Journal of European Public Policy, 25(1), 100-118.

Lima, A. P., Manichard, F., \& Reyes, V. (2017, January 20). Bi-culturele transgenders in de amsterdamse samenleving een eerste verkenning [Bi-cultural transgender people in Amsterdam society a first exploration]. Amsterdam: COC. Retrieved from https:// www.cocamsterdam.nl/wp-content/uploads/2017/ 01/COC-Rapport-Bi-culturele-trensgenders-DEF.pdf

Meulmeester, G., Bos, G., Spaas, J.-P., \& Eisfeld, J. (2005). Doe $T$ zelf [Do $T$ yourself]. Amersfoort: Stichting T-Image.

Orobio de Castro, I. (1993). Made to order: Sex/gender in a transsexual perspective. Amsterdam: Het Spinhuis.

Osterburg, M., \& Kiel, C. (2017). A hegemon fighting for equal rights: The dominant role of COC Nederland in the LGBT transnational advocacy network. Global Networks, 17(2), 234-254.
Partzsch, L. (2015). Innovators for the public: How norm and social entrepreneurs fulfill the promises of democracy. In I. Narbutaité-Aflaki, E. Petridou, \& L. Miles (Eds.), Entrepreneurship in the polis: Understanding political entrepreneurship (pp. 171-189). Hampshire: Ashgate.

Pauly, I. B. (1993). Terminology and classification of gender identity disorders. Journal of Psychology \& Human Sexuality, 5(4), 1-14.

Plate, W. P. (1954). Het verlangen om van geslacht te veranderen [The desire to change sex]. Nederlands Tijdschrift voor Geneeskunde, 98(11), 726-727.

Principle 17. (2016). P17 survey: Trans health care in the Netherlands. Amsterdam: Principle 17. Retrieved from Principle 17: principle17.org/en/report

Steenwinkel, F. (1960). Plastische operatie ter verandering van het fenotypisch geslacht [Plastic surgery to change the phenotypic sex]. Nederlands Tijdschrift voor Geneeskunde, 104(6), 302.

Stoller, R. J. (1968). Sex and gender: On the development of masculinity and femininity. New York, NY: Science House.

The Yogyakarta Principles. (2017). The Yogyakarta principles plus 10. Geneva: The Yogyakarta Principles. Retrieved from http://yogyakartaprinciples.org/wpcontent/uploads/2017/11/A5_yogyakartaWEB-2.pdf

UN. (2011, July 14). Human rights, sexual orientation and gender identity (A/HRC/RES/17/19). New York, NY: United Nations.

van Bijsterveldt-Vliegenthart, J. (2011, April 8). Homoemancipatiebeleid. Brief van de Minister van Onderwijs, Cultuur en Wetenschap [Gay Emancipation Policy: Letter from the Minister of Education, Culture and Science]. The Hague: Ministry of Education, Culture and Science.

van der Reijt, F. (1982). Transsexualiteit in Nederland: Een ontwerp van wet [Transsexuality in the Netherlands: A draft of the law]. Medisch Contact, 37(24), 115-118.

van der Vleuten, A. (2005). Pincers and prestige: Explaining the implementation of EU gender equality legislation. Comparative European Politics, 3(4) 464-488.

van der Vleuten, A., van Eerdewijk, A., \& Roggeband, C. (2014). Gender equality norms in regional governance: Transnational dynamics in Europe, South America and Southern Africa. Basingstoke: Palgrave Macmillan.

van Emde Boas, C. (1974). De behandeling van transseksisten in Nederland 1953-1973: Een les van 20 jaar attitudes schommelingen [Treating transsexists in the Netherlands in 1953-1973: A lesson of 20 years of fluctuating attitudes]. Medisch Contact, 29, 475.

van Garrel, B. (1992, December 24). Gesprek met Otto van de Vaal, medicus en kunstverzamelaar [Conversation with Otto van de Vaal, physician and art collector]. NRC, 73. Retrieved from https://www.nrc.nl/ nieuws/1992/12/24/gesprek-met-otto-de-vaalmedicus-en-kunstverzamelaar-10443164-a961741 
Verloo, M., \& Lombardo, E. (2007). Contested gender equality and policy variety in Europe: Introducing a critical frame analysis approach. In M. Verloo (Ed.), Multiple meanings of gender equality: $A$ critical frame analysis of gender policies in Europe (pp. 21-50). Budapest: Central European University Press.

Verschoor, A. (1983). Wijziging van geboorteakte van transseksuelen [The change of transsexuals' birth cer- tificates]. Tijdscr Seksuol, 7(1), 24-30.

Willems, E. (Producer). (2013). Transgender Pioneers [Television series episode]. In Andere Tijden. Hilversum: Nederlandse Publieke Omroep.

World Professional Association for Transgender Health. (2019). International symposia. World Professional Association for Transgender Health. Retrieved from https://www.wpath.org/about/history/internationalsymposia

\section{About the Author}

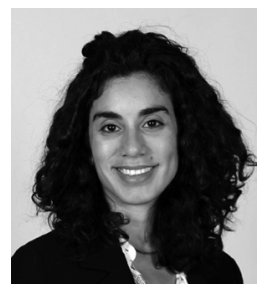

Melisa Soto-Lafontaine is PhD Candidate in the Department of Political Sciences at the Radboud University Nijmegen (the Netherlands). In her current research project, she studies the diffusion and contestation of trans norms in the Netherlands and Cuba. She is particularly interested in the roles of political actors, their contesting frames and the mechanisms underlying norm change. She co-authored the article "Sexual Self-Determination in Cuba: The Epistemic Decolonial Turn" in Sexualities (with Carmona Baez, 2015) and has conducted research on reproductive technologies from an empirical ethics approach. 